\title{
UN predicts long wait to repair environment
}

\section{Virginia Gewin}

The benefits of some environmentally friendly policies will not be apparent until decades after they have been enacted. That is one of the messages of a report from the United Nations Environment Programme, which, even by the standards of global environment assessments, is sobering reading.

Global Environmental Outlook 3 (GEO3), a study of the links between environmental, social and development issues, contains a range of dire but familiar predictions about the impact of factors such as climate change and industrial development. But the report, released last week in the run-up to August's World Summit on Sustainable Development in Johannesburg, was unusually pessimistic about the prospects for reversing the damage.

The new predictions are contained in one of four possible futures outlined in the report. The authors considered scenarios in which global politics were dominated by concerns over either markets, environmental and social policies, security or sustainability. These were based on attempts to quantify the effect of the different approaches on population levels, economics, technology and governance.

Some of the scenarios produced a famil-

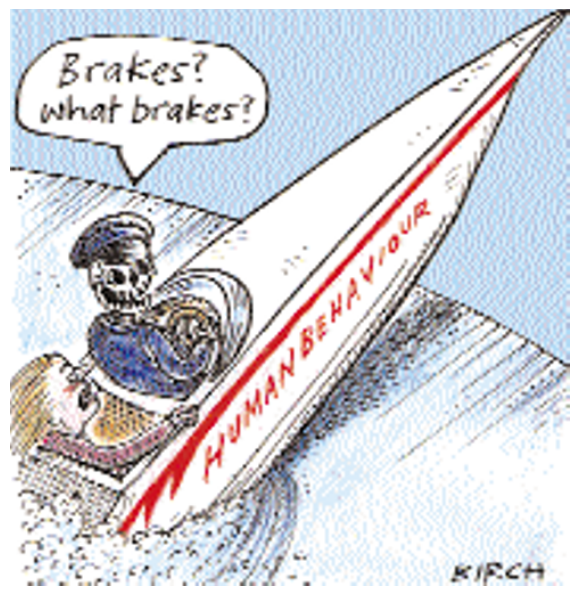

iar picture. In a world dominated by a market mentality, for example, land and forest degradation becomes a critical issue, particularly in Latin America and the Caribbean.

But the sustainability scenario's predictions shocked some of the authors. "The delays between changing human behaviour and environmental recovery came as the biggest surprise to the regional experts," says Jan Bakkes of the National Institute of Public Health and the Environment in Bilthoven, the
Netherlands, one of the report's authors.

The report found that even if environmentally friendly approaches were adopted now, carbon dioxide concentrations would continue to rise until 2050. Water shortages would continue and coastal pollution would increase slightly. Bakkes blames difficulty in altering energy and transport infrastructures.

Originally used during the 1950 s to simulate future conflicts, scenarios were revived in an improved form by the Intergovernmental Panel on Climate Change (IPCC) in the early 1990s. "By adding scenarios to assessments you come up with a credible story about how the world might evolve and can translate that into quantifiable information," says Bert Metz, also at the Bilthoven institute and co-chair of the IPCC working group on strategies for tackling climate change.

More than 1,000 scientists contributed to GEO-3, which divides the world into no less than 17 different regions. By contrast, the IPCC has used just four regions in previous assessments, although the panel's new chair, energy economist Rajendra Pachauri, has pledged to improve regional detail in future studies (see Nature 417, 106; 2002).

www.unep.org/GE0/ge03

\section{Scientists placated as US bill gets tough on bioterror}

\section{Virginia Gewin, Washington}

Eight months after the anthrax attacks that brought the bioterrorist threat into sharp relief, the US Congress has passed a \$4.6billion bill to prepare for future assaults. It includes measures to control researchers' access to microbes that can be used as weapons - but scientific societies say they

\section{are happy with the new legislation.}

Under the bill, researchers from countries listed by the Department of State as sponsors of terrorism - Cuba, Iran, Iraq, Libya, North Korea, Sudan and Syria - will be banned from working on 42 microbes and toxins in US labs. Anyone with a criminal record will also be excluded, and security for

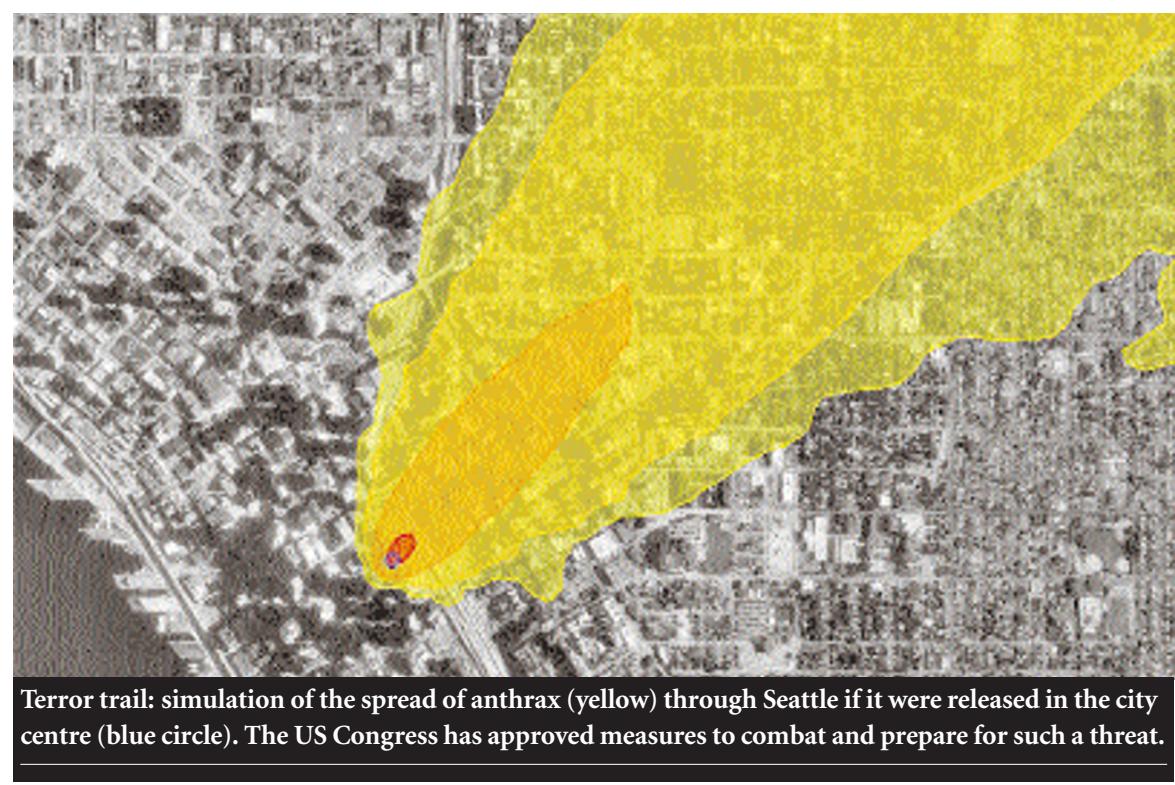

labs working with the agents will be stepped up. A national database will also be created to monitor research on these agents.

Last autumn, the House of Representatives backed a bill to prevent all non-citizens apart from permanent residents from working with the agents - which alarmed scientists who felt this would restrict legitimate research (see Nature 414, 3-4; 2001). But scientific societies are satisfied with the final legislation. "We feel pleased that Congress has worked with us to come up with a reasonable set of regulations," says Janet Shoemaker, director of public and scientific affairs for the American Society for Microbiology.

The bill also provides funds for stockpiling drugs and vaccines, and for improving drinking-water security. To protect the food supply, funding will be provided for research and training to detect, prevent and respond to agricultural bioterrorism. As part of this effort, an early-warning system will coordinate diagnostic labs, agricultural research facilities and public-health agencies.

The bill also addresses terrorism against animal experiments. "We are pleased that it includes increased criminal penalties for terrorist activities against animal facilities," says Jordan Cohen, president of the Association of American Medical Colleges. 